\title{
PENSANDO A OPERACIONALIZAÇÃO DE ESTUDOS SOBRE CIDADES DO AGRONEGÓCIO
}

\author{
PENSER À L'OPÉRATIONNALISATION DES ÉTUDES SUR LA CITÉ DE \\ L'AGROBUSINESS
}

\author{
Denise Elias $^{\mathrm{A}}$ \\ ${ }^{\text {A }}$ Universidade Estadual do Ceará (UECE), Fortaleza, CE, Brasil
}

Recebido em: 29/11/2021 |04/01/2022 DOI: $10.12957 /$ tamoios.2022.63811

Correspondência para: Denise Elias (deniseliasgeo@gmail.com)

\begin{abstract}
Resumo
O agronegócio globalizado é um dos principais vetores da reorganização do território brasileiro, notadamente desde os anos de 1980, gerando inúmeras novas relações campo-cidade, processos de (re)estruturação urbano-regional, de (re)estruturação de muitas cidades, assim como de formação de novas cidades em função das demandas impostas pelos agentes hegemônicos desse agronegócio. O principal objetivo deste artigo é refletir sobre possibilidades de operacionalização de pesquisas sobre o que chamamos de cidade do agronegócio. Entendemos que os estudos sobre esse tipo de cidade podem ser organizados a partir de diferentes eixos, dentre os quais: reestruturação produtiva da agropecuária; o consumo produtivo do agronegócio; a composição do setor industrial; a dinâmica populacional; a dinâmica do mercado de trabalho; a reestruturação da cidade; as desigualdades socioespaciais na escala intraurbana. Embora tais temas sejam indissociáveis, essa subdivisão constitui um importante recurso metodológico, que viabiliza a realização da pesquisa. No entanto, para que se obtenha êxito em um trabalho científico, além de sua operacionalização, é preciso que a pesquisa seja calcada em sólidas bases teórico-conceituais e abrangente diálogo com os agentes da produção do espaço.
\end{abstract}

Palavras-chave: agronegócio globalizado; cidade do agronegócio; metodologia; Brasil.

\section{RESUMÉ}

L'agrobusiness mondialisé est l'un des principaux vecteurs de la réorganisation du territoire brésilien, notamment depuis les années 1980, générant d'innombrables nouvelles relations campagne-ville, des processus de (re)structuration urbaine-régionale, de (re)structuration de nombreuses villes, ainsi que comme de formation de villes nouvelles en fonction des exigences imposées par les agents hégémoniques de cette agrobusiness. L'objectif principal de cet article est de réfléchir aux possibilités d'opérationnalisation de la recherche sur ce que nous appelons la cité de l'agrobusiness. On comprend que les études sur ce type de ville peuvent être organisées à partir de différents axes, parmi lesquels: restructuration productive de l'agriculture; la consommation productive de l'agrobusiness; la composition du secteur industriel; les dynamiques de population; la dynamique du marché du travail; la restructuration de la ville; inégalités socio-spatiales à l'échelle intra-urbaine. Bien que ces thèmes soient indissociables, cette subdivision constitue une ressource méthodologique importante, qui permet réussite la recherche. Cependant, pour réussir un travail scientifique, en plus de son opérationnalisation, la recherche doit s'appuyer sur des bases théoriques-conceptuelles solides et un dialogue approfondi avec les agents de la production spatiale.

Mots clés: agrobusiness mondialisée; cité de l'agrobusiness; méthodologie; Brasil. 


\section{INTRODUÇÃO}

No presente artigo, sistematizamos algumas ideias relacionadas às nossas linhas de pesquisa que abordam o incremento da urbanização da sociedade e do território associado à difusão do agronegócio globalizado (ELIAS, 2003), visando analisar as dinâmicas de produção dos espaços agrícolas, urbanos e regionais inerentes a esse agronegócio. Aqui, compartilhamos as formas como operacionalizamos algumas das pesquisas realizadas sobre o que chamamos de cidades do agronegócio (ELIAS, 2006, 2007, 2010, 2016).

As cidades do agronegócio compõem as regiões produtivas do agronegócio (ELIAS, 2006, 2011, 2016) e têm passado por uma intensa reestruturação produtiva de suas atividades agropecuárias e por mudanças nas formas de uso e ocupação do solo nas últimas cinco décadas, no contexto da revolução tecnoagrícola e dos novos signos do período técnico-científico-informacional (SANTOS, 1996), sob o comando de corporações transnacionais do agronegócio.

Embasamo-nos na tese de que, nesse intervalo de tempo, o agronegócio tem sido um dos principais vetores da reorganização do território brasileiro, especialmente desde a década de 1980, sendo responsável pela reestruturação do espaço não só agrícola, mas também urbano e regional em diferentes partes do Brasil. O agronegócio também tem criado novas relações campo-cidade, promovendo processos de (re)estruturação urbano-regional, de (re)estruturação de muitas cidades, além de formar novas cidades em função das demandas impostas pelos agentes hegemônicos desse setor (ELIAS, 2006, 2016, 2017a).

A noção de cidade do agronegócio é uma derivação de cidade do campo, proposto por Milton Santos (1988, 1993, 2000). Utilizamos essa noção por cerca de dez anos, mas, desde o final dos anos 1990, preferimos substituí-la por cidade do agronegócio, para melhor explicitar a quais agentes e interesses a produção de tais cidades se associa, buscando melhor consolidar conceitualmente essa noção. ${ }^{1}$

Este artigo é composto por duas seções, além desta introdução e das considerações finais. A primeira seção apresenta brevemente ao leitor o que chamamos de cidade do agronegócio, enquanto a segunda discute questões associadas a possibilidades de operacionalização de pesquisas sobre cidades do agronegócio, a partir um conjunto de eixos temáticos.

\section{A cidade do agronegócio}

Considerando a complexa rede de atividades que compõe o agronegócio globalizado (agropecuárias, industriais, comerciais e de serviços especializados), é notório que seus 
sistemas de objetos e sistemas de ação (SANTOS, 1996) não se localizem somente no campo, mas também em cidades de vários estratos da rede urbana brasileira.

A análise dos circuitos espaciais de produção e dos círculos de cooperação (SANTOS, 1986) do agronegócio globalizado evidencia a formação de redes geográficas a ele associadas. De maneira geral, como parte dessas redes, temos as regiões produtivas do agronegócio (RPAs) e as cidades do agronegócio que, por sua vez, constituem os espaços urbanos não metropolitanos inseridos nas RPAs, nos quais se dá a gestão local e regional do agronegócio.

A cidade do agronegócio é um espaço urbano não metropolitano, resultado dos processos inerentes às novas formas de uso e ocupação do território brasileiro, associados à reestruturação produtiva da agropecuária e à expansão da economia e da sociedade do agronegócio. Essas cidades exercem centralidade urbana nas RPAs, ou seja, constituem um elo entre amplos espaços agrícolas - extremamente racionalizados com altos índices de ciência, tecnologia, informação e capital - e o espaço urbano-regional. Assim, as cidades do agronegócio devem ser estudadas a partir de suas interações com os espaços agrícola e regional. Ao mesmo tempo, elas constituem nós da rede de cidades associadas ao agronegócio globalizado, que reúne de cidades pequenas a metrópoles regionais e globais (ELIAS, 2017b).

A cidade é a materialização das condições gerais de reprodução do capital (CARLOS, 2004). Adaptando as ideias de Santos (1985), a cidade do agronegócio é, ao mesmo tempo, estrutura, processo, função e forma para a reprodução do capital do agronegócio globalizado e, desse modo, uma força produtiva para sua reprodução ampliada (ELIAS, 2007). Constitui-se, assim, um nó fundamental na rede de relações econômicas, sociais, políticas e de logística do agronegócio (ELIAS, 2005, 2006, 2007, 2010, 2012, 2015, 2016).

Para Corrêa (2010), a especialização de uma cidade pode ser captada mediante a leitura de suas funções urbanas. As cidades do agronegócio são especializadas devido às múltiplas demandas impostas pelos agentes do agronegócio, que têm poder de impor especializações econômicas e espaciais cada vez mais profundas. Assim, as cidades do agronegócio são aquelas cujas funções inerentes ao agronegócio são hegemônicas sobre as demais funções. ${ }^{2}$

Em virtude de cada commodity apresentar necessidades específicas de produtos e serviços (por exemplo, as da soja são diferentes das da cana-de-açúcar, que diferem das do milho que, por sua vez, são distintas das de produção de frutas tropicais etc.), as cidades do agronegócio são cada vez mais especializadas e, a despeito de haver inúmeras similitudes entre elas, suas respectivas economias urbanas apresentam relevantes distinções entre si.

O consumo produtivo do agronegócio (ELIAS, 2003, 2009, 2015; ELIAS; PEQUENO, 2010) mostra isso e ressalta demandas heterogêneas, segundo as necessidades de produção (agropecuária ou agroindustrial) de cada produto nas diferentes etapas do processo 
produtivo, diferenciando, muitas vezes, os ramos do comércio e dos serviços associados à expansão das atividades do agronegócio.

Os estudos sobre o consumo produtivo apareceram primeiro em Marx (1982), associados à reprodução dos meios de produção. Elencamos tal tema como estruturante para melhor compreender o peso do agronegócio na economia urbana, assim como alguns dos mais importantes processos econômicos e espaciais a ele associados. Esse tipo de consumo está diretamente ligado às condições gerais de produção do agronegócio, sendo inerente à reprodução dos meios de produção (bens e serviços) para a consecução do agronegócio. Assim, nos lugares onde se processam a reestruturação produtiva da agropecuária e a difusão do agronegócio globalizado, é recorrente que as cidades expandam suas economias urbanas associadas ao consumo produtivo do agronegócio. O crescimento desses comércios e serviços está entre os vetores de incremento não só da economia urbana, mas também pode ser apontado como fator causal da (re)estruturação de várias cidades, de novas relações campo-cidade, do incremento da urbanização e de processos de (re)estruturação urbano-regional em regiões onde o agronegócio é relevante na economia e na produção do espaço (ELIAS, 2020a).

De maneira geral, nas cidades do agronegócio, localizam-se as indústrias esmagadoras de soja, os frigoríficos de aves e suínos, as lojas de insumos e máquinas agrícolas, os bancos especializados em crédito para o agronegócio etc. Essas cidades também abrigam os trabalhadores agrícolas não rurais, os trabalhadores especializados e os funcionários das agroindústrias.

A economia urbana inerente ao consumo produtivo do agronegócio na cidade de Petrolina, em Pernambuco, que comanda importante região produtora de frutas tropicais (especialmente uva e manga), guarda pouca semelhança com a economia urbana de cidades associadas, por exemplo, à produção e transformação industrial da soja, como Luis Eduardo Magalhães, na Bahia (que compõe o Matopiba), ou Sorriso, no Mato Grosso do Sul, entre outros exemplos. Por isso, não existe cidade do agronegócio, mas cidades do agronegócio.

As especializações e funções exercidas pelas diferentes cidades do agronegócio podem ser mais facilmente percebidas durante as distintas etapas do processo produtivo, por exemplo, na safra e na entressafra. É no período de safra das principais culturas de uma região produtiva do agronegócio que podemos melhor distinguir sua especialização. Trata-se do momento mais dinâmico nas várias cidades do agronegócio, afetando todos os setores econômicos e gerando uma enorme quantidade de fluxos de várias naturezas (pessoas, capital, informação, matérias-primas etc.). Exemplo disso é o funcionamento ininterrupto - durante 24 horas - de muitas agroindústrias, cuja manutenção se dá apenas durante a entressafra, como ocorre com o setor sucroenergético. No período da colheita, também aumentam os empregos agrícolas temporários, especialmente referente às culturas nas quais a mecanização ainda não predomina, como das frutas (uva, banana, melão), entre outras. 
Algumas cidades comandadas pelo agronegócio são reestruturadas e refuncionalizadas a partir de sua difusão. Como exemplos, podemos citar como Barreiras, principal cidade no oeste da Bahia, Balsas (MA) e Chapecó (SC). Outros municípios, especialmente em áreas de fronteira agrícola, são compostos de núcleos urbanos recém-criados, já sob influência da difusão do setor, nascendo associados à economia e à sociedade do agronegócio, como é o caso de Luís Eduardo Magalhães, que se desmembrou de Barreiras, em 2000, ou de várias cidades no Mato Grosso, situadas às margens da BR 163, como Nova Mutum e Lucas do Rio Verde. Também é possível identificar várias outras cidades, situadas nas diferentes regiões do Brasil, cujo crescimento econômico e territorial das últimas duas ou três décadas se deveu diretamente à consecução do agronegócio globalizado. É o caso de Uruçuí (PI), Sorriso (MT), Matão e Sertãozinho (SP), Rio Verde (GO), Dourados (MS), entre outras (ELIAS, 2003, 2006, 2015).

Apesar de todo o dinamismo econômico característico de uma cidade do agronegócio, ela é - adaptando algumas noções trabalhadas por Milton Santos (1993) - um mero lugar do fazer do agronegócio globalizado, ou seja, ocupa uma posição inferior na cadeia de comando do setor. Nela, se realiza a gestão mais imediata necessária à produção agropecuária e agroindustrial inerentes ao agronegócio, mas, mesmo que participe dos circuitos espaciais globalizados da produção de alguma importante commodity, as cidades do agronegócio ocupam posição subalterna na divisão social da economia do agronegócio. ${ }^{3}$

$\mathrm{Na}$ rede de cidades associadas ao agronegócio, o comando se concentra nas principais metrópoles do mundo, o que indica que cidades globais estão no topo da hierarquia dessa rede. É nessas cidades onde se localizam, por exemplo, as sedes das corporações transnacionais, as matrizes dos fundos de investimento com atuação no setor, as bolsas de valores e mercadorias, entre outros.

No Brasil, embora a cidade de São Paulo seja o epicentro do comando do agronegócio, esta é somente um elo subalterno na cadeia de comando centralizado em alguns poucos países de origem das corporações do setor (ELIAS, 2017b). De qualquer forma, isso reforça nossa tese da crucial importância que a cidade e a economia urbana têm para a reprodução do capital do agronegócio (ELIAS, 2003, 2020a).

Considerando que o agronegócio é espacialmente seletivo, economicamente concentrador e socialmente excludente (ELIAS, 2002), as cidades do agronegócio são exemplos do que Santos (1993) chamava de produção de espaços corporativos, no caso, sob comando das corporações transnacionais à frente do setor (Cargill, Bunge, ADM, BRF, John Deer, Bayer, JBS, entre outras). Isso indica que as verticalidades são predominantes sobre as horizontalidades, assim como a solidariedade organizacional prevalece sobre a solidariedade orgânica. ${ }^{4}$ Dessa forma, os capitais do agronegócio têm cada vez mais domínio sobre as terras, a tecnologia, a logística, os trabalhadores e, naturalmente, as esferas locais de poder das cidades do agronegócio, assim como grande ingerência sobre a produção do espaço urbano, além de agrícola e regional. 
Pelo exposto, a cidade do agronegócio muito claramente revela uma nova face da pobreza estrutural, ${ }^{5}$ apresentando as desigualdades socioespaciais como um de seus signos mais expressivos. Esse é um recorte espacial que nos permite analisar a inserção passiva do país na economia e no consumo globalizados.

\section{Operacionalizando uma pesquisa sobre a cidade do agronegócio}

É sempre um grande desafio refletir sobre como operacionalizar as noções, os conceitos e as categorias de uma pesquisa científica. Por mais difícil que sejam as etapas de uma pesquisa, elas são mais exequíveis do que o estudo do objeto de pesquisa em si, uma vez que, com muita disciplina e dedicação, é possível realizá-las. Mas, no momento de transpor a teoria para o objeto de estudo, de imbricar o teórico com o empírico, surgem alguns complicadores. Por essa razão, é essencial que nos preocupemos com a metodologia e a operacionalização de um trabalho científico.

É importante vislumbrar a pesquisa como um todo desde o início. Isso não é uma tarefa fácil, uma vez que, por vezes, só conseguimos enxergar sua totalidade ao final do estudo, quando já não é mais possível promover mudanças ou realizar determinadas ações, especialmente considerando os prazos, cada vez menores, exigidos para os estudos científicos. Mesmo assim, é crucial identificar, desde o início do trabalho, seu conjunto de temas, processos e agentes importantes para a pesquisa, assim como as variáveis, os indicadores e as fontes de comprovação para cada um deles. Para facilitar seu desenvolvimento, sempre iniciamos uma pesquisa elencando questões norteadoras que servirão de guia para o estudo e que devem ser respondidas ao longo de sua execução (ELIAS, 2020a). Dessa forma, temos mais chances de atingir os objetivos pré-estabelecidos na fase do projeto de pesquisa.

Isso é ainda mais importante em relação a estudos de grande complexidade, como os que tratam das cidades do agronegócio. Afirmamos isso por entendermos que tais estudos não cabem nas tradicionais "caixinhas" da Geografia, como a Geografia Agrária, a Geografia Urbana, a Geografia Econômica ou a Geografia Regional, pois englobam todas essas subáreas e ainda outras, o que é um complicador para a realização da pesquisa. Deve-se considerar, ainda, a dificuldade de se selecionar os aportes teórico-conceituais, uma vez que é necessário trabalhar com um conjunto expressivo de conceitos e categorias de cada uma dessas subáreas. Assim, consideramos importante discutir sobre como operacionalizamos uma pesquisa referente às cidades do agronegócio.

De nosso ponto de vista, um estudo sobre esse tema pode ser baseado em alguns eixos, como reestruturação produtiva da agropecuária, consumo produtivo do agronegócio, composição do setor industrial, dinâmica populacional, dinâmica do mercado de trabalho, (re)estruturação da cidade e desigualdades socioespaciais na escala intraurbana. Embora tais temas sejam indissociáveis, suas subdivisões constituem um importante recurso metodológico, que facilitam o desenvolvimento das pesquisas científicas da área. Também é 
importante destacar que um único estudo não precisa, necessariamente, abarcar todos os eixos, sendo possível focar em apenas um deles ou em pares associados, como dinâmica populacional e mercado de trabalho ou reestruturação da cidade e desigualdades socioespaciais no intraurbano, por exemplo.

Mesmo que nem todos os eixos sejam objeto de estudo diretos de uma pesquisa, não há como abordar um ou alguns deles sem, efetivamente, compreender a totalidade dos processos associados. Essa visão da totalidade constitui uma questão de método importante para qualquer pesquisa. Muitas vezes, a visão da totalidade dos processos associados a uma cidade do agronegócio pode ser adquirida através de uma revisão bibliográfica, com consultas a teses ou dissertações de boa qualidade, já que hoje, diferentemente do que ocorria há 30 anos, os estudos sobre o agronegócio vêm crescendo, sendo possível ter acesso a muitos deles através da internet.

A seguir, discorreremos sobre alguns aspectos de cada eixo citado.

\section{Reestruturação produtiva da agropecuária}

Em se tratando de cidades do agronegócio, é fundamental conhecer como se dão as atividades que direcionam a existência de tais municípios e como ocorrem o uso e a ocupação do espaço agrícola de sua região produtiva. Assim, recomendamos as seguintes questões norteadoras: Quais as principais culturas produzidas? Está havendo mudanças das formas de uso e ocupação do solo? Quais são as condições técnicas da produção? Quais são os agentes à frente da produção? Observam-se a territorialização do capital e a monopolização do território pelos agentes do agronegócio? Quais são as características da estrutura fundiária? Observam-se conflitos no campo associados à reestruturação produtiva da agropecuária? Tais aspectos refletem-se diretamente nas cidades e em suas respectivas regiões de influência.

Esse eixo nos permite avaliar as características, os ritmos e as consequências socioespaciais resultantes do processo de reestruturação produtiva da agropecuária, sem dúvida uma das vias de reconhecimento das transformações da sociedade e do território brasileiros dos últimos 50 anos. Desde então, organiza-se e difunde-se o modelo de produção denominado agronegócio. Esse eixo permite avaliar também um vasto conjunto de processos ligados à desestruturação da formação socioespacial anterior, à difusão da economia, da sociedade e do território do agronegócio globalizado.

Esse eixo temático inclui diversas variáveis e indicadores, como o número e a área dos estabelecimentos agropecuários segundo classes de utilização da terra; a área plantada e a produção; a condição legal das terras; a estrutura fundiária; o preço da produção; o destino da produção; estabelecimentos que utilizam máquinas agrícolas; percentual de estabelecimentos agrícolas com acesso à eletrificação; percentual de estabelecimentos que utilizam insumos químicos, sementes selecionadas, agrotóxicos; número de estabelecimentos empresariais 
associados à agropecuária; número de empregos formais da agropecuária; população ocupada nos estabelecimentos agropecuários; o preço da terra; número de armazéns e silos; PIB agrícola em relação ao PIB municipal, entre outros.

É importante ressaltar que o recorte espacial deve considerar alguns municípios que compõem a região produtiva na qual a cidade se insere, enquanto o recorte temporal precisa abarcar um período que explicite as mudanças ocorridas nas formas de uso e ocupação do espaço agrícola. Assim, recomenda-se que os estudos incluam no mínimo dois anos, sendo um antes do início das mudanças e outro mais próximo possível do momento da pesquisa. Idealmente, deve-se incluir um ano intermediário entre os dois, visando melhor avaliar as mudanças e seus ritmos.

Através dessas variáveis e indicadores, é possível captar os processos de reestruturação produtiva da agropecuária, as dinâmicas do mercado de terras e de organização da estrutura fundiária, as metamorfoses das formas de uso e ocupação do solo, assim como os agentes à frente de tais processos e as mudanças das relações sociais de produção.

A caracterização desse eixo também fornece elementos para o estudo de elementos basilares de outros eixos, como os processos de desterritorialização das populações que originalmente ocupavam a região e que são expulsas do campo, caracterizando, por exemplo, os deslocamentos demográficos, cruciais para os estudos da dinâmica populacional.

Quanto às fontes de dados a serem consultadas com relação a esse tema, recomendamos os Censos Agropecuários e a Produção Agrícola Municipal, produzidos pelo IBGE, e a Relação Anual de Informações Sociais (RAIS), do Ministério do Trabalho e Emprego (MTE). Além dessas fontes oficiais, é possível obter informações através de trabalhos de campo, imprescindíveis para pesquisas sobre cidades ou regiões do agronegócio; relatórios e visitas técnicas às secretarias municipais e estaduais de agricultura, desenvolvimento econômico; documentos de jornais especializados; entrevistas e conversas com os diferentes agentes associados ao agronegócio, dos empresariais aos excluídos pelo processo de reestruturação produtiva, sindicatos patronais e movimentos de trabalhadores, entre outros. $^{6}$

\section{Consumo produtivo do agronegócio}

Nas áreas onde se processam a reestruturação produtiva da agropecuária e a difusão do agronegócio globalizado, é comum que as cidades desenvolvam novas funções e expandam suas economias associadas ao consumo produtivo do agronegócio. O estudo desse eixo promove uma melhor compreensão das cidades do agronegócio. Esse tipo de consumo está diretamente associado às condições gerais de produção do agronegócio, ou seja, aquelas inerentes à reprodução dos meios de produção (bens e serviços) para a consecução do agronegócio. 
O crescimento dos comércios e serviços associados às demandas do agronegócio está entre os vetores de incremento da economia urbana, além de determinar novas relações campo-cidade. Esses comércios e serviços também promovem o aumento da urbanização, a (re)estruturação de cidades e a (re)estruturação urbano-regional em áreas nas quais o agronegócio é relevante na economia e na produção do espaço.

Entre as questões norteadoras importantes para o eixo, podemos destacar: Quais serviços e comércios estão intrinsecamente associados ao consumo produtivo do agronegócio? Qual a importância desse consumo produtivo mediante o consumo total da cidade estudada? Qual o percentual das casas comerciais e dos serviços voltados ao agronegócio perante o terciário total? Qual o destaque do ensino técnico e tecnológico associado ao agronegócio em relação ao número total de cursos e matrículas? É possível detectar quanto dos empréstimos realizados nas agências bancárias se associam ao agronegócio? É possível observar hegemonia dos estabelecimentos comerciais e de serviços inerentes ao consumo produtivo no que tange ao número de estabelecimentos e ao valor bruto das operações? Existem comércios e serviços inerentes ao agronegócio associados ao circuito superior da economia urbana? As instituições associadas às redes de poder do agronegócio estão presentes na cidade?

O número de variáveis e indicadores é grande para o eixo. Como exemplo, citamos alguns serviços associados às demandas do agronegócio: empresas de pesquisa agropecuária; análise de solos; aviação agrícola; consultoria agrícola; montagem de sistemas de irrigação; leilões de gado; manutenção de máquinas agrícolas; empresas de transporte de cargas; escritórios de exportação; cursos técnicos e superiores voltados às demandas do agronegócio, desde os mais tradicionais, como de veterinária, até os mais recentes, como os inerentes às agtechs - as startups voltadas ao agronegócio, entre tantos outros. Também são muito presentes os estabelecimentos comerciais, como os de máquinas agrícolas, de sementes selecionadas, de agrotóxicos, de fertilizantes, entre vários outros.

Em relação às fontes de dados, há maior complexidade para obtenção das informações, especialmente sobre os serviços, seja pela quantidade, diversidade ou tipo de fontes oficiais que permitem a construção de séries históricas. Em muitos casos, é necessária a coleta de informações primárias, através de trabalho de campo ou da consulta a outras fontes, como associações comerciais, sindicatos, documentos das empresas etc. Entre as fontes possíveis, podemos citar: a RAIS, a Pesquisa de Estoques do IBGE, o MEC/Inep, os jornais de circulação diária com acesso via internet, revistas especializadas, associações comerciais, trabalhos de campo e visitas técnicas a empresas, sindicatos patronais e feiras agropecuárias, entre outros. ${ }^{7}$

\section{Composição do setor industrial}


Esse eixo também é muito relevante, mas não se aplica necessariamente a todas as cidades do agronegócio, já que nem sempre as produções agropecuárias apresentam fortes relações com o setor industrial. Por exemplo, embora seja essencial para as áreas de produção de soja, a composição do setor industrial não é um elemento importante para áreas voltadas para a produção de frutas tropicais no Nordeste, como a região do Baixo Jaguaribe (CE) e de Mossoró (RN).

É importante destacar que esse eixo representa uma clássica característica da expansão do capitalismo no campo: a subordinação crescente da agropecuária à indústria (KAUTSKY, 1980; OLIVEIRA, 2010). O setor industrial destaca-se não só na economia industrial, mas se associa cada vez mais à economia agrícola de muitas cidades do agronegócio, uma vez que alguns segmentos da agropecuária se encontram monopolizados pelo capital agroindustrial, como ocorre com a produção de soja, a avicultura, a pecuária leiteira, a produção de coco e de castanha de caju, entre outras, que dominam parcelas crescentes da produção agropecuária para beneficiamento, processamento ou transformação.

É possível dividir as agroindústrias em dois grandes ramos: agroindústria alimentar e não alimentar. Ambos cresceram muito no Brasil, paralelamente à reestruturação produtiva da agropecuária. Uma consulta à $\mathrm{CNAE}^{8}$ nos permitiu identificar 16 grupos de atividades da indústria de transformação que podem ser classificadas como agroindústria. Desses, nove estão associados à agroindústria alimentar e sete à não alimentar, sendo que cada grupo se desdobra em várias classes. ${ }^{9}$

Por outro lado, é crescente a dependência da agropecuária como consumidora de produtos industrializados, como máquinas agrícolas, fertilizantes, agrotóxicos, sementes geneticamente modificadas, entre outros. Vários desses ramos industriais podem ser encontrados em cidades do agronegócio, especialmente os agroindustriais.

Algumas questões norteadoras contribuem para o estudo do setor industrial nas cidades do agronegócio: Qual o percentual de agroindústrias e de indústrias de bens de capital para o agronegócio perante o número total de estabelecimentos e empregos industriais? Qual o nível de capital e de tecnologia das indústrias associadas ao agronegócio? Qual a origem do capital das agroindústrias? As matérias-primas das agroindústrias são provenientes da região produtiva na qual a cidade está inserida? Qual o destino da produção agroindustrial? Quando existente, a produção das indústrias de bens de produção é consumida localmente? As indústrias associadas ao agronegócio são importantes quanto à arrecadação do ICMS?

Estudos e pesquisas já realizados por nós (ELIAS, 2003, 2020b) permitem indicar alguns processos fundamentais a serem estudados: crescimento do número de estabelecimentos e de empregos industriais relacionados aos ramos associados ao agronegócio, diversificação das classes da agroindústria alimentar, ampliação da concentração econômica no segmento agroindustrial, formação de corporações agroindustriais alimentares, incremento do poder econômico e político das corporações agroindustriais, monopolização da 
produção agropecuária pelas corporações agroindustriais alimentares e aumento das relações campo-cidade promovidas pelas corporações agroindustriais, entre outros.

Quanto às variáveis e aos indicadores referentes a esses processos, podemos citar: número de estabelecimentos e empregos agroindustriais; número de empregos e estabelecimentos segundo grupos e classes da agroindústria; número de empregos por estabelecimento segundo faixas de número de empregos; número de empresas com mais de 500 empregados (indicador que permite classificar o estabelecimento como de grande porte); distribuição espacial dos estabelecimentos e dos empregos da agroindústria; percentual de domínio da produção agropecuária por parte das agroindústrias; fluxos de trabalhadores, matérias-primas e insumos realizados entre o local da produção agropecuária e as sedes das agroindústrias; quantidade de estabelecimentos e empregos da indústria fornecedora de bens de produção ao agronegócio, entre outros.

Destacamos duas fontes importantes para trabalhar esse eixo: a Classificação Nacional de Atividades Econômicas (CNAE) e a Relação Anual de Informações Sociais (RAIS), do Ministério do Trabalho e Emprego (MTE). ${ }^{10}$ A primeira é base para identificarmos e selecionarmos os diferentes grupos e classes de atividades da indústria de transformação que diretamente se associam ao agronegócio, enquanto a segunda nos fornece informações sobre os números de estabelecimentos e empregos formais, segundo as atividades econômicas e os municípios.

Como para todos os eixos, também é essencial a formação de uma hemeroteca que proporcione um conjunto de informações referentes ao tema e ao objeto de estudo, notadamente com suas características mais atuais. Da mesma forma, informações disponibilizadas pelas empresas (planos estratégicos, relatórios etc.) contribuem para o melhor entendimento do funcionamento das atividades produtivas. ${ }^{11}$

\section{Dinâmica populacional}

Passadas cerca de cinco décadas do início da difusão do agronegócio no Brasil, entendemos que não há dúvidas quanto a seu impacto sobre a dinâmica populacional do país. Tal realidade é totalmente perceptível nas regiões e cidades do agronegócio, onde se observam novos movimentos populacionais, com significativos crescimentos das populações total e urbana; diminuição expressiva da população rural, com fortes movimentos do campo para as cidades; intensos processos de migração descendente (de cidades maiores para cidades menores), muito fortemente associados às demandas do agronegócio por mão de obra especializada, de origem e vivências urbanas, o que faz das cidades do agronegócio locais de concentração de uma gama diversificada de profissionais especializados com maior qualificação.

Entre as questões norteadoras a serem adotadas nesse eixo, destacamos: Como se dá a dinâmica populacional na região e cidade do agronegócio? Como evoluiu a taxa de 
urbanização após a chegada do agronegócio? Como se dá a evolução da população total, urbana e rural? Quais as principais características dos processos migratórios? É possível observar a presença de migrantes sazonais? Como se processam os fluxos diários de trabalhadores agrícolas não rurais? A difusão do agronegócio contribuiu para o êxodo rural? Como a exigência de mão de obra especializada para o agronegócio influencia no processo de migração descendente? Qual a origem da mão de obra especializada que chega para trabalhar no agronegócio? Como se dá a distribuição dos migrantes segundo gênero?

Entre as variáveis e indicadores, destacam-se: contingente de população total, urbana e rural; taxa de urbanização; número de pessoas residentes urbanas não nascidas no município; município de origem; dentre outros. Para esse eixo, os Censos Demográficos e outras pesquisas do IBGE, tais como projeções e estimativas da população, constituem as fontes principais.

\section{Dinâmica do mercado de trabalho}

O mercado de trabalho é um tema que nos ajuda a revelar muito não só da cidade, mas também da própria região produtiva do agronegócio, especialmente considerando as relações campo-cidade; a formação de um mercado de trabalho agrícola formal, até então pouco significativo em muitas áreas do Brasil, notadamente nas fronteiras agrícolas; a evolução da mão de obra especializada associada ao agronegócio e o crescimento de novas categorias de trabalhador agrícola, como o agrícola não rural, que mora na cidade e trabalha no campo, evidenciando, entre outros aspectos, as mudanças das relações sociais de produção promovidas pela difusão do agronegócio. A dinâmica do mercado de trabalho compõe um eixo totalmente imbricado com alguns outros, como da dinâmica populacional, do consumo produtivo do agronegócio e da composição do setor industrial.

As principais questões norteadoras para esse eixo são: Qual o percentual dos empregos formais gerados pelo agronegócio em seus diferentes segmentos? Quanto da PEA associada ao terciário está empregada no comércio e nos serviços especializados para o agronegócio? Como se dá a participação da PEA agrícola na PEA total? Como se observam a formação e a difusão do mercado de trabalho agrícola formal, segundo dados da RAIS/CAGED? Quais atividades associadas ao agronegócio oferecem mais empregos formais durante o período da safra? Em que grau se verifica a exigência de mão de obra especializada para o agronegócio? Quais as características do sistema de produção flexível - como de terceirização e subcontratação - podem ser observadas a partir da difusão do agronegócio? Os períodos de maior nível de emprego coincidem com os períodos de safra das principais culturas associadas ao agronegócio? Quais as relações possíveis entre os diferentes níveis de emprego e as diferentes fases do calendário agrícola? Como se manifestam o subemprego e o desemprego no período de entressafra? Observa-se a existência de trabalho análogo à escravidão? 
Como variáveis e indicadores, destacamos: pessoas residentes em áreas urbanas ocupadas no setor agropecuário; mão de obra agrícola não rural sem qualificação; quantidade de mão de obra especializada ocupada na agropecuária; número de empregos, estabelecimentos comerciais e serviços associados à agropecuária; PEA; população ocupada nos estabelecimentos agropecuários, entre outros. As principais fontes para esse eixo são os dados da RAIS e dos Censos Demográfico e Agropecuário. ${ }^{12}$

\section{(Re)estruturação da cidade}

Esse eixo também é bastante complexo e permite uma aproximação com estudos sobre a economia política da cidade, sendo possível observar, de maneira geral, as formas de atuação dos diferentes agentes produtores do espaço da cidade, as disputas e arranjos entre eles e como a produção da cidade se processa no tempo e no espaço.

Para o estudo da (re)estruturação da cidade, é crucial considerarmos os sistemas de objetos e os sistemas de ação. Devem ser levantados dados relativos à presença ou ausência das infraestruturas e equipamentos nas cidades, bem como dos espaços de moradia e consumo que refletem em novas práticas socioespaciais em espaços urbanos não metropolitanos.

A chegada de novos agentes econômicos associados ao agronegócio exige toda sorte de implantação de sistemas de objetos com vistas a fornecer maior fluidez ao território, multiplicando os fixos e os fluxos de diferentes naturezas nas cidades do agronegócio. Ocorre, assim, uma ampliação e modernização das infraestruturas e equipamentos para gerar suporte ao desenvolvimento das atividades agrícolas e agroindustriais, especialmente associadas aos transportes, às comunicações, à eletrificação e ao saneamento, expandindo a materialidade do território e a rede de relações nas quais se inserem as cidades.

Se, por um lado, aumentam os sistemas de objetos associados às demandas do agronegócio, considerando a nova dinâmica populacional e do mercado de trabalho, com crescimento da população urbana e total, paralelamente ocorre também a difusão dos fixos inerentes às demandas da população de maneira geral, embora em diferentes velocidades e qualidades, restando muitas desigualdades no que tange ao atendimento à produção e à população, ou seja, entre o consumo produtivo e o consumo consumptivo (SANTOS, 1988), considerando o desenvolvimento desigual e combinado característico do capitalismo.

Entre tantas questões norteadoras, podemos citar: Quais elementos se destacam na estruturação das cidades estudadas? Como ocorre a implantação da logística para o agronegócio (rodovias, portos secos, terminais intermodais, silos, armazéns etc.)? A chegada e difusão das atividades associadas ao agronegócio promoveram redefinições dos centros tradicionais, assim como a formação de subcentros na estrutura da cidade (com a instalação de shopping-centers, supermercados, hotéis de rede, franquias, universidades privadas, agências bancárias, condomínios fechados etc.)? Houve uma reestruturação do centro 
tradicional da cidade (com a construção de centros culturais, teatros, ginásio de esportes etc.)? O consumo produtivo do agronegócio gera um subcentro associado aos produtos e serviços especializados para o setor? Qual a infraestrutura instalada (aeroportos, portos, rodovias, portos secos, ferrovias, hidrovias, terminais portuários) concernente às horizontalidades e verticalidades das empresas e corporações do agronegócio (fluxos de ordens, conhecimento, informação, mercadorias, matérias-primas)? Houve expansão da oferta de infraestrutura, serviços urbanos e equipamentos sociais com a chegada dos agentes do agronegócio? Há vazios urbanos próximos às áreas de maior concentração de infraestrutura? O uso residencial ainda remanesce na área central? De que maneira o mercado imobiliário tem atuado? De que forma o processo de planejamento urbano do município vem sendo conduzido quanto à promoção da regularização fundiária e ao combate à especulação imobiliária? Quais agentes têm se destacado em relação à questão da moradia e quais são seus papéis e interesses? $\mathrm{O}$ plano diretor prevê a existência de distritos agroindustriais? Como as leis de diretrizes dos transportes regula o aumento do transporte de carga? Como as leis urbanísticas da cidade lidam com a existência de grandes plantas industriais em áreas centrais? Quais as principais características das leis de uso e ocupação do solo da cidade?

As próprias questões norteadoras do eixo identificam suas variáveis e indicadores. Quanto às fontes de dados, há um conjunto de informações secundárias, produzidas em especial por instituições públicas, como: IBGE, Fundação João Pinheiro, Portal Brasileiro de Dados Abertos, Secretaria Nacional de Portos e Transportes Aquaviários, Agência Nacional de Avião Civil, Associação Brasileira de Shopping-Center (ABRASCE), Associação Brasileira de Supermercados (ABRAS) e Ministério da Educação (MEC).

Por outro lado, há uma vasta gama de informações que precisam ser diretamente pesquisadas junto às prefeituras e secretarias municipais, especialmente através da realização de trabalho de campo. Essas fontes são compostas por Planos Diretores, Leis de Parcelamento e de Uso e Ocupação do Solo, Código de Obras, Planos Setoriais (mobilidade, habitacional, de saneamento), entre outras. Durante os trabalhos de campo, diálogos com os gestores públicos devem ser realizados, pois podem fornecer informações importantes para a pesquisa.

Cabe ainda destacar a presença de grandes projetos urbanos (GPU) vinculados à logística, à infraestrutura e a grandes equipamentos de uso coletivo. Apesar de restritos a um determinado recorte espacial, por vezes, estes suplantam em importância os processos de planejamento territorial relativos à totalidade do município. Tais projetos têm sido utilizados para a implementação de parcerias público-privadas, sempre com o intuito de atrair investidores, mas sem que os benefícios sejam distribuídos com a totalidade do município. ${ }^{13}$

\section{Desigualdades socioespaciais na escala interurbana}

Nas regiões produtivas do agronegócio, o campo e a cidade revelam as novas faces da pobreza estrutural (ELIAS, 2006). De maneira geral, as cidades do agronegócio reproduzem os mesmos problemas urbanos das cidades maiores, além de 
produzirem novas e mais complexas desigualdades.

\begin{abstract}
Destacaríamos: ausência ou insuficiência de equipamentos sociais (creches, escolas, postos de saúde) nas áreas habitadas pela população de menor renda; favelização nos espaços destinados a usos institucionais e áreas verdes; surgimento de áreas de ocupação em situação de risco ambiental; disseminação de vazios urbanos atrelados à especulação imobiliária; loteamentos periféricos clandestinos desprovidos de infraestrutura; congestionamento nas áreas centrais por movimentação de carga e descarga, entre outros (ELIAS; PEQUENO, 2016a, p.391).
\end{abstract}

Assim, outro tema imprescindível para estudo de uma cidade do agronegócio é o da desigualdade socioespacial. Assim como nas demais cidades brasileiras, o estudo da desigualdade socioespacial nas cidades do agronegócio inclui diversas variáveis.

Realizamos algumas pesquisas sobre esse eixo juntamente com o arquiteto e urbanista Renato Pequeno (UFC). Nossa primeira pesquisa conjunta, realizada em meados dos anos 2000, considerava a difusão do agronegócio e novas dinâmicas socioespaciais em áreas que até então compunham parte do que Santos (1993) chamava de exército de lugares de reserva, especialmente em regiões do Cerrado nordestino, que posteriormente passaram a ser chamadas de Matopiba, com a expansão da rede agroindustrial da soja, da mesma forma que nos vales úmidos do Semiárido, com a produção de frutas tropicais voltadas para exportação (regiões do Baixo Jaguaribe - CE e Baixo Açu - RN; Petrolina - PE e Juazeiro - BA). Durante essa pesquisa, realizamos um conjunto de trabalhos de campo que incluíram alguns municípios diretamente associados ao agronegócio. ${ }^{14}$

Segundo Pequeno (2010, 2015), a moradia é a variável que melhor explicita o estágio de desigualdades socioespaciais no espaço urbano. Assim, essa foi a variável escolhida para traduzir as disparidades nas cidades do agronegócio, em algumas das pesquisas que realizamos em conjunto. Ainda de acordo com o autor e, considerando critérios propostos por Corrêa $(1995,2013)$, a análise da produção da moradia pode ser realizada segundo os diferentes agentes da produção do espaço, que consideram: a força dos grupos hegemônicos vinculados ao setor imobiliário privado, a pertinência e os impactos da produção de interesse social pelo Estado e a produção em condições precárias pelos grupos excluídos (PEQUENO; ELIAS, 2020), que Pequeno $(2010,2015)$ traduz como a cidade produzida pelo mercado imobiliário, a cidade das políticas habitacionais de interesse social e a cidade informal e precária. Novamente, destacamos que tais separações correspondem a um recurso metodológico utilizado para facilitar a compreensão dos processos espaciais segundo os diferentes agentes, reconhecendo que estes são totalmente interligados e interdependentes.

Sobre as questões norteadoras, muitas das citadas em relação ao eixo anterior também auxiliam na compreensão das desigualdades socioespaciais nas cidades do agronegócio. Entre as principais perguntas não citadas, destacamos: Como as políticas urbana e habitacional foram conduzidas nas últimas três décadas? Como a questão da moradia se manifesta, 
considerando os diferentes agentes da produção do espaço? Onde se localizam os vazios urbanos? Qual o tamanho desses vazios urbanos? Já se observa o processo de verticalização associado à moradia na cidade? É possível encontrar espaços ocupados por grupos autossegregados? Há setores onde predomina a habitação social de mercado? A cidade possui conjuntos habitacionais originários de políticas públicas? Como são as condições de moradia das populações excluídas? Existem loteamentos periféricos clandestinos desprovidos de infraestrutura? Há ocupação de áreas em situação de risco ambiental? Registram-se ausência ou insuficiência de infraestrutura urbana, serviços e equipamentos sociais nas áreas habitadas pela população de menor renda?

Uma pesquisa sobre as desigualdades socioespaciais tendo a moradia como variável-chave exige um esforço de síntese a partir da análise de um vasto conjunto de dados secundários, produzidos por instituições públicas, assim como de informações que precisarão ser pesquisadas junto ao setor privado, como as empresas do setor imobiliário. O trabalho de campo também é imprescindível para a obtenção de dados primários, aumentando as chances de se alcançar resultados promissores, que reflitam da forma mais fidedigna possível a realidade da desigualdade socioespacial das cidades estudadas.

Entre as fontes produzidas pelas instituições públicas, podemos citar, entre outras: os estudos da Fundação João Pinheiro sobre as características do déficit habitacional; os estudos e programas do extinto Banco Nacional da Habitação (BNH); os vários documentos que compõem os planos diretores dos municípios; a Lei de Parcelamento; a Lei de Uso e Ocupação do Solo; os programas habitacionais apoiados pela Caixa Econômica Federal (CEF) ou pelo Banco do Brasil junto às prefeituras e aos respectivos governos estaduais; os programas de urbanização de favelas, incluindo as remoções e o reassentamento de populações de áreas ocupadas. Ressaltamos a importância de se investigar o conteúdo das políticas urbana e habitacional no sentido de identificar possíveis instrumentos urbanísticos capazes de enfrentar as disparidades, atenuar as precariedades e atender às demandas por ventura localizadas.

Entre as informações para pesquisa em trabalhos de campo, destacamos: a existência de imobiliárias com a dinamização do mercado urbano de terras e de moradias, inclusive para aluguel; os principais lançamentos das construtoras (de loteamentos fechados e edifícios); a presença e o peso dos vazios urbanos; a existência da verticalização; os estudos sobre o déficit habitacional, as condições inadequadas de moradia e os domicílios vagos; o mapeamento de assentamentos urbanos precários, ocupados pela população excluída pelas políticas públicas; a existência de cortiços, favelas, conjuntos habitacionais inacabados e loteamentos irregulares e clandestinos, inclusive promovidos pelos agentes do mercado imobiliário formal. ${ }^{15} \mathrm{E}$ importante mencionar que, atualmente, algumas dessas informações podem ser obtidas via internet. 


\section{CONSIDERAÇÕES FINAIS}

Longe da pretensão de esgotar o assunto ou desenvolver um debate teórico-conceitual, buscamos apresentar de forma concisa aspectos possíveis para a operacionalização de estudos sobre cidades do agronegócio. É importante destacar que os processos inerentes à difusão do agronegócio são extremamente dinâmicos e muitas das realidades citadas poderão não mais corresponder à realidade por ocasião de uma outra pesquisa, não invalidando, apesar disso, a compreensão dos processos e de sua totalidade.

O objetivo principal deste artigo foi contribuir com jovens pesquisadores que estejam iniciando seus estudos sobre o tema e, muitas vezes, se sentem perdidos diante da complexidade da realidade e do próprio método científico, sem saber exatamente como operacionalizar as noções e conceitos-chave de suas pesquisas. Da mesma forma, objetivamos promover o debate sobre o tema das cidades do agronegócio, visando aperfeiçoar os procedimentos metodológicos possíveis para as pesquisas desenvolvidas na área.

\section{AGRADECIMENTOS}

Agradecemos ao Conselho Nacional de Desenvolvimento Científico e Tecnológico (CNPq) pelo apoio a várias de nossas pesquisas que serviram de base para o presente artigo. Também agradecemos ao professor Dr. Renato Pequeno, coordenador do Laboratório de Estudos da Habitação (LEHAB) do Departamento de Arquitetura e Urbanismo da Universidade Federal do Ceará (UFC), nosso parceiro em algumas dessas pesquisas, pela leitura, comentários e sugestões.

\section{NOTAS}

1 - Milton Santos concebe as cidades do campo como aquelas capazes de oferecer resposta imediata às necessidades técnicas, científicas, informacionais e logísticas do campo modernizado (SANTOS, 1994).

2 - Em uma cidade do agronegócio, não é incomum conseguirmos comprar uma colheitadeira de última geração, produzida por uma corporação transnacional, mas não encontramos um jornal impresso da capital do Estado ao qual a cidade pertence.

3 - Sobre a economia do agronegócio, consultar Delgado (2012).

4 - Sobre horizontalidades e verticalidades, solidariedades orgânicas e organizacionais, consultar Santos $(1993,1996)$.

5 - Para Santos (2000, p. 56), atualmente, vive-se uma pobreza que "[...] resulta da convergência de causas que se dão em diversos níveis, existindo como vasos comunicantes”. Por isso, merece o nome de pobreza estrutural globalizada. Trata-se da forma concreta de 
manifestação da pobreza no período da globalização que se sustenta por meio de uma nova construção discursiva e se reproduz segundo as singularidades históricas de cada país.

6 - A reestruturação produtiva da agropecuária e a organização da agricultura científica já foi por nós estudada em algumas pesquisas. Por exemplo, foi o tema do capítulo 2 de nossa tese de doutorado, quando estudamos a região de Ribeirão Preto, que consideramos o exemplo mais complexo de região produtiva do agronegócio do Brasil (ELIAS, 2003).

7 - Em algumas de nossas pesquisas, consideramos o consumo produtivo do agronegócio em diferentes partes do país (ELIAS, 2003, 2009, 2015; ELIAS; PEQUENO, 2010).

8 - "A CNAE é o instrumento de padronização nacional dos códigos de atividade econômica e dos critérios de enquadramento utilizados pelos diversos órgãos da Administração Tributária do país. Trata-se de um detalhamento da CNAE - Classificação Nacional de Atividades Econômicas, aplicada a todos os agentes econômicos que estão engajados na produção de bens e serviços, podendo compreender estabelecimentos de empresas privadas ou públicas, estabelecimentos agrícolas, organismos públicos e privados, instituições sem fins lucrativos e agentes autônomos (pessoa física)" (BRASIL, 2014).

9 - Para saber quais são os grupos e classes da agroindústria alimentar, consultar Elias (2020b).

10 - O MTE disponibiliza vários dados sobre o mercado de trabalho formal brasileiro, como os contidos na RAIS, sobre o número de empregos formais e estabelecimentos contratantes.

11 - Como exemplo de pesquisa na qual trabalhamos com o setor industrial associado ao agronegócio, podemos citar Elias (2003, 2020b).

12 - Entre os resultados de pesquisas sobre esse eixo, podemos citar: Elias; Pequeno; Romcy (2012) e Bezerra; Elias (2011).

13 - Entre as pesquisas nas quais tratamos da reestruturação urbana de cidades associadas ao agronegócio, podemos citar: Elias; Pequeno (2016ab) e Pequeno; Elias (2020).

14 - Barreiras, Luís Eduardo Magalhães, Correntina, São Desidério, Formosa do Rio Preto (BA); Uruçuí (PI); Balsas (MA); Limoeiro do Norte, Russas, Icapuí e Quixeré (CE) e Mossoró e Ipanguaçu (RN).

15 - Entre os registros de nossas pesquisas sobre desigualdades socioespaciais em regiões e cidades do agronegócio, podemos citar: Elias (2003, 2006), Elias; Pequeno (2005, 2006, 2007, 2010, 2016ab, 2018) e Pequeno; Elias (2020).

\section{REFERÊNCIAS}

BEZERRA, Juscelino E.; ELIAS, Denise. Difusão do trabalho agrícola formal no Brasil e sua dinâmica multiescalar. Investigaciones Geográficas, n. 76, p. 104-117, 2011. 
CARLOS, Ana Fani Alessandri. O espaço urbano. Novos escritos sobre a cidade. São Paulo: Editora Contexto, 2004. 154p.

CORRÊA, Roberto Lobato. Espaço urbano. São Paulo: Ática, 1995. 240p.

CORRÊA, Roberto Lobato. Inovações espaciais urbanas - algumas reflexões. Cidades, n. 11, v. 7, 2010.

CORRÊA, Roberto Lobato. Segregação residencial: classes sociais e espaço urbano. In VASCONCELOS, Pedro de Almeida; PINTAUDI, Silvana Maria; CORRÊA, Roberto Lobato (Org.). A cidade contemporânea. São Paulo: Contexto, 2013.

DELGADO, Guilherme. Do capital financeiro na agricultura à economia do agronegócio: mudanças cíclicas em meio século (1965-2012). Porto Allegre: Ed. UFRGS, 2012. 142p.

ELIAS, Denise. Integração competitiva do semiárido cearense. In ELIAS, Denise; FURTADO, José Levi Sampaio. (Org.). Modernização excludente. Fortaleza: Demócrito Rocha, 2002. p.15-43.

ELIAS, Denise. Globalização e agricultura. São Paulo: Edusp, 2003. 400p.

ELIAS, Denise. Agronegócio e desigualdades socioespaciais. In ELIAS, Denise; PEQUENO, Renato (Org.). Difusão do agronegócio e novas dinâmicas socioespaciais. Fortaleza: BNB/Etene, 2006. 484p. Disponível em: https://www.observatoriodasmetropoles.net.br/wp-content/uploads/2020/07/EBOOK-DIFUS A\%CC\%83O-AGRO-NE.pdf.

ELIAS, Denise. Fronteiras em mutação no Brasil Agrícola. In FELDMAN, Sarah; FERNANDES, Ana (Org.). O urbano e o regional no Brasil contemporâneo: mutações, tensões, desafios. Salvador: EDUFBA, 2007. p. 135-151.

ELIAS, Denise. Reestruturação produtiva da agropecuária e urbanização dispersa no Brasil. In SANFELIU, Carmen Bellet; SPOSITO, Maria Encarnação Beltrão (Org.). Las ciudades medias o intermedias em um mundo globalizado. Lleida: Edicions de la Universitat de Lleida, 2009. p. 87-105.

ELIAS, Denise. O Brasil agrícola com áreas urbanas: a cidade do agronegócio. In OLIVEIRA, José Ademir (Org.). Cidades brasileiras. Manaus: UFAM, 2010. p.147-164.

ELIAS, Denise. Agronegócio e novas regionalizações no Brasil. Revista Brasileira de Estudos Urbanos e Regionais (ANPUR), v. 13, p. 153-170, 2011.

ELIAS, Denise. Consumo produtivo em Regiões do Agronegócio do Brasil. In: BELLET, Carmen; MELAZZO, Everaldo; SPOSITO, Maria Encarnação Beltrão; LLOP, Josep Maria (Org.). Urbanización, producción y consumo em ciudades medias/intermedias. Lleida: Edicions de la Universitat de Lleida, 2015. p. 35-56.

ELIAS, Denise. Agronegócio e reestruturação urbana e regional no Brasil. In BUHLER, Eve Anne, GUIBERT, Martine; OLIVEIRA, Valter Lúcio (Org.). Agriculturas empresariais e espaços rurais na globalização. Porto Alegre: Ed. UFRGS, 2016. p. 63-82. 
ELIAS, Denise. Agronegócio globalizado e (re)estruturação urbano-regional. In: XVII ENANPUR, 2017, São Paulo. Anais do XVII ENANPUR. São Paulo: ANPUR, 2017a. p. $1-16$.

ELIAS, Denise. Agronegócio globalizado: do campo a metrópole. In: FERREIRA, Álvaro; RUA, João; Mattos, Regina Célia (Org.). O espaço e a metropolização. Rio de Janeiro: Consequência, 2017b. p. 487-509.

ELIAS, Denise. A Região Metropolitana como recorte espacial para estudos sobre o agronegócio: questões de método e metodologia. Boletim Goiano de Geografia, v. 40, p. $1-28,2020 \mathrm{a}$.

ELIAS, Denise. Agroindústria alimentar: epicentro do agronegócio no Estado do Ceará (Brasil). Confins (PARIS), v. 1, p. 1-24, 2020b.

Elias, Denise; PEQUENO, Renato. Espaço urbano no Brasil agrícola moderno e desigualdades socioespaciais. Terra Livre, Goiânia, v. 2, n. 25, p. 13-33, 2005.

ELIAS, Denise; PEQUENO, Renato. (Orgs.). Difusão do Agronegócio e novas dinâmicas socioespaciais. Fortaleza: BNB/Etene, 2006. 484p. Disponível em: https://www.observatoriodasmetropoles.net.br/wp-content/uploads/2020/07/EBOOK-DIFUS A\%CC\%83O-AGRO-NE.pdf.

ELIAS, Denise; PEQUENO, Renato. Desigualdades socioespaciais nas cidades do agronegócio. Revista Brasileira de Estudos Urbanos e Regionais (Anpur), v. 9, n. 1, p. 25-39, 2007.

ELIAS, Denise; PEQUENO, Renato. Mossoró: o novo espaço da produção globalizada e aprofundamento das desigualdades socioespaciais. In SPOSITO, Maria Encarnação; ELIAS, Denise; SOARES, Beatriz Ribeiro (Org.). Agentes econômicos, reestruturação urbana e regional: Passo Fundo e Mossoró. São Paulo: Expressão Popular, 2010. p. 101-283.

ELIAS, Denise; PEQUENO, Renato. Desigualdades socioespaciais nas cidades do agronegócio. In ROLNIK, Raquel; FERNANDES, Ana (Org.). Cidades. Rio de Janeiro: Funarte, 2016a. p. 383-402.

ELIAS, Denise; PEQUENO, Renato. (Re)estruturação urbana e desigualdades socioespaciais em região e cidade do agronegócio. GEOgraphia (UFF), v. 17 n. 35, p. 10-39, 2016 b.

ELIAS, Denise; PEQUENO, Renato. Reestruturação produtiva e do território de Mossoró (RN). In ELIAS, Denise.; PEQUENO, Renato (Org.). Tendências da urbanização brasileira: novas dinâmicas de estruturação urbano-regional. Rio de Janeiro: Letra Capital, 2018. p. $59-100$

ELIAS, Denise; PEQUENO, Renato; ROMCY, Priscila de Oliveria. Rupturas na rede urbana e faces do mercado de trabalho. Geotextos (Online), v. 8, p. 2012-145, 2012.

KAUTSKY, K. A questão agrária. 3. ed. São Paulo: Proposta Editorial, 1980.

MARX, Karl. Introdução [À Crítica da Economia Política]. In MARX, Karl. Contribuição para a crítica da economia política. São Paulo: Abril Cultural, 1982 [1859]. (Coleção Os Pensadores). 
OLIVEIRA, Ariovaldo Umbelino. Agricultura e indústria no Brasil. Campo-Território, v. 5, n. 10, p. 5-64, 2010.

PEQUENO, Renato. Condição de moradia: retrato das desigualdades socioespaciais. In Oliveira, José Ademir (Org.). Cidades Brasileiras: territorialidades, sustentabilidade e demandas sociais. Manaus: Editora da UFAM, 2010. p. 40-56.

PEQUENO, Renato. Condições de moradia e desigualdades socioespaciais: o caso de Fortaleza. In Pequeno, Renato; Costa, Maria Clélia Lustosa (Org.). Fortaleza: transformações na ordem urbana. Rio de Janeiro: Letra Capital: Observatório das Metrópoles, 2015. p. $238-282$

PEQUENO, Renato; ELIAS, Denise. (2020). Estruturação urbana e questão da moradia nas cidades do agronegócio. GeoTextos, vol. 16, n. 1, 2020. p. 109-136.

SANTOS, Milton. Espaço e método. São Paulo: Nobel, 1985.

SANTOS, Milton. Circuitos espaciais da produção: um comentário. In: SOUZA, Maria Adélia Aparecida de; SANTOS, Milton (Org.). A construção do espaço. São Paulo: Nobel, 1986.

SANTOS, Milton. Metamorfoses do espaço habitado. São Paulo: Hucitec, 1988.

SANTOS, Milton. A urbanização brasileira. São Paulo: Hucitec, 1993.

SANTOS, Milton. Técnica, Espaco, Tempo. Globalizacão e meio técnico-científico-informacional. São Paulo: Editora Hucitec, 1994.

SANTOS, Milton. A natureza do espaço. São Paulo: Hucitec, 1996.

SANTOS, Milton. Por uma outra globalização. Rio de Janeiro: Record, 2000.

\section{COMO CITAR ESTE TRABALHO}

ELIAS, Denise. Pensando a operacionalização de estudos sobre cidades do agronegócio.

Revista Tamoios, São Gonçalo, v. 18, n. 1, p. 144-164, 2022. Disponível em: https://doi.org/10.12957/tamoios.2022.63811. Acesso em: DD MMM. AAAA. 